\title{
CCCS-SSAI WikiRecs Clinical Practice Guideline: vasopressors in early traumatic shock
}

\author{
Bram Rochwerg, MD (D) Mathieu Hylands, MD • Morten Møller, MD • Pierre Asfar, MD • \\ Dian Cohen • Rachel G. Khadaroo, MD · John H. Laake, MD - Anders Perner, MD • \\ Teddie Tanguay, RN $\cdot$ Sandy Widder, MD $\cdot$ Per Vandvik, MD $\cdot$ Annette Kristiansen, MD • \\ François Lamontagne, MD
}

Received: 29 July 2016/Revised: 16 October 2016/Accepted: 11 April 2017/Published online: 11 May 2017

(C) Canadian Anesthesiologists' Society 2017

PICO $^{\mathrm{A}}$ Question: Should early vasopressors be used vs not used in adult trauma patients with hypotension?

Recommendation: The panel did not make a recommendation for this question.

This is a recommendation developed by the Canadian Critical Care Society and the Scandinavian Society of Anaesthesiology and Intensive Care Medicine (CCCS-

This is a recommendation developed by the Canadian Critical Care Society and the Scandinavian Society of Anaesthesiology and Intensive Care Medicine according to standards for trustworthy guidelines in collaboration with the MAGIC WikiRecs project. An abridged version of the guideline is published in Intensive Care Medicine (10.1007/s00134-016-4539-5).

This article is accompanied by an editorial. Please see Can J Anesth 2017; 64: this issue.

Electronic supplementary material The online version of this article (doi:10.1007/s12630-017-0879-z) contains supplementary material, which is available to authorized users.

B. Rochwerg, MD ( $\square)$

Department of Medicine, Faculty of Health Sciences, McMaster University, Hamilton, ON, Canada

e-mail: rochwerg@mcmaster.ca

B. Rochwerg, MD

Department of Clinical Epidemiology and Biostatistics,

McMaster University, Hamilton, ON, Canada

M. Hylands, MD - F. Lamontagne, MD

Université de Sherbrooke, Sherbrooke, QC, Canada

M. Møller, MD · A. Perner, MD

Department of Intensive Care, Copenhagen University Hospital

Rigshospitalet, Copenhagen, Denmark
SSAI) according to standards for trustworthy guidelines in collaboration with the MAGIC WikiRecs project. The WikiRecs project is an ongoing collaborative effort by a network of expert clinicians and methodologists whose aim is to produce trustworthy evidence summaries and clinical practice recommendations within 90 days of identifying potentially practice-changing evidence. See www. magicapp.org/public/guideline/OLwWKL for more details about methods and processes, full evidence summary (GRADE SoF-table), and practical information presented in multilayered formats-available on all digital devices. The electronic supplemental material also contains similar information expanding on the WikiRecs methods and processes.

Justification: A systematic review of the literature, including both blunt and penetrating trauma, found multiple observational trials examining this clinical question $^{1-4}$ and a single randomized-controlled trial $(\mathrm{RCT}){ }^{5}$ Although the observational data suggest increased short-term mortality associated with the use of

\section{P. Asfar, MD}

Medical Intensive Care Department, University Hospital of Angers, Angers, France

D. Cohen

Massawippi Valley Health Centre, Ayers Cliff, QC, Canada

R. G. Khadaroo, MD - S. Widder, MD

Department of Surgery and Critical Care Medicine, University of Alberta, Edmonton, AB, Canada

\footnotetext{
${ }^{A}$ PICO is defined as: Population, Intervention, Comparator, Outcome.
} 
Table Evidence profile outlining outcomes studied, pooled relative and absolute estimates of effect, GRADE certainty rating, and summary statement

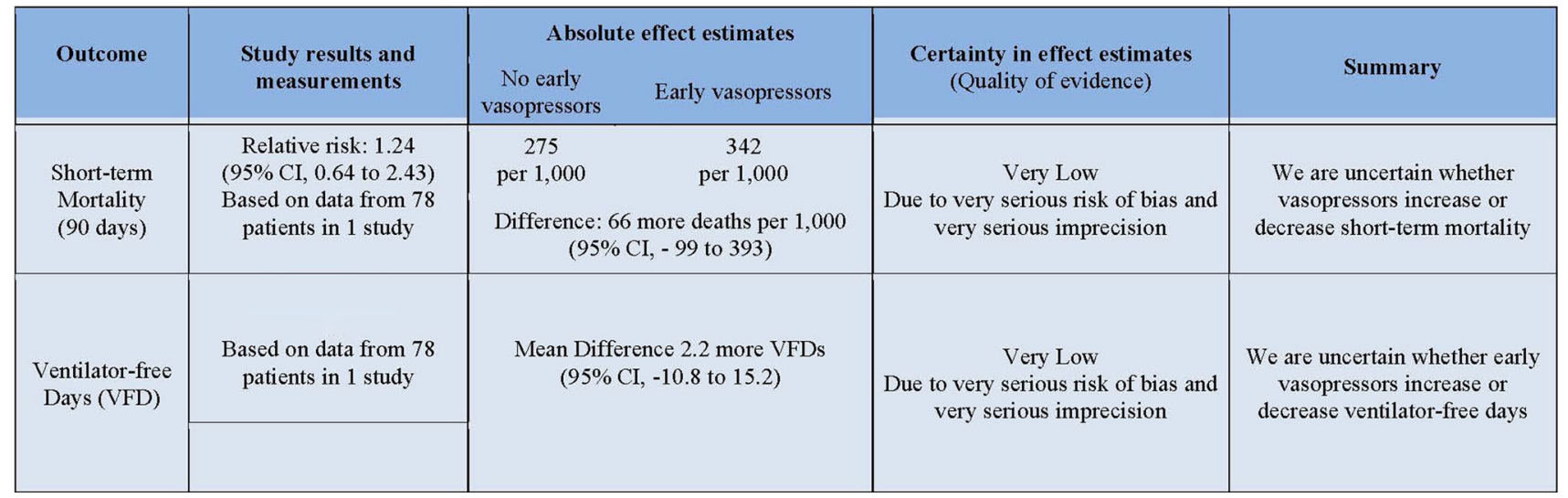

CI - confidence interval

vasopressors (three studies; 1,711 patients; relative risk, 4. 97; $95 \%$ CI, 2.95 to 8.37 ; very low certainty in estimates), the panel's assessment was that the RCT provided more informative evidence than the observational studies due to the overwhelming concern for residual confounding bias in the non-randomized trials. ${ }^{6}$ Despite starting as high quality, point estimates from the RCT for the outcomes of mortality and ventilator-free days ended with very low certainty (see Table). These were secondary to concerns related to the potential risk of bias (imbalance between baseline prognostic markers, significant loss to follow-up, and the fact the trial was stopped early due to slow accrual of patients) and significant imprecision.

\section{J. H. Laake, MD}

Anaesthesiology, Division of Critical Care, Oslo University Hospital, Oslo, Norway

\section{T. Tanguay, RN}

Canadian Association of Critical Care Nurses, Edmonton, AB, Canada

P. Vandvik, MD · A. Kristiansen, MD

Faculty of Medicine, University of Oslo, Oslo, Norway

\section{P. Vandvik, MD}

Norwegian Knowledge Centre for the Health Services, Oslo, Norway

P. Vandvik, MD · A. Kristiansen, MD

Department of Medicine, Innlandet Hospital Trust-Division, Gjøvik, Norway

\section{F. Lamontagne, MD}

Centre de recherche du Centre Hospitalier Universitaire de Sherbrooke, Sherbrooke, QC, Canada
As all estimates are based on data with very low certainty, it is very difficult to assess the balance between net benefits and harms from use of vasopressors in this population. Also, some relevant outcomes, such as worsening organ ischemia and rates of arrhythmia, were not captured by the included trial. We lack data on longterm morbidity and quality-of-life indices, which severely limits our ability to make a recommendation. Highlighting the uncertainty of this question, there is currently a high degree of variability in clinical practice, with significant geographical variation regarding the use of early vasopressors in trauma patients. ${ }^{7}$

Understanding both the lack of demonstrated benefit and the fact that the use of vasopressors may be associated with increased resources and potential harm, there was a significant amount of discussion amongst the panel regarding the appropriateness of a conditional recommendation against use. Ultimately, given the high degree of uncertainty, the guideline panel decided to offer no recommendation at this time. Obviously, as with any clinical question, if additional data become available, this issue may be re-addressed. Future research is needed to inform this question.

Conflicts of interest None declared.

Editorial responsibility This submission was handled by Dr. Hilary P. Grocott, Editor-in-Chief, Canadian Journal of Anesthesia.

Author contributions Bram Rochwerg contributed by chairing the guideline panel, helping to employ GRADE methodology and certainty of evidence assessments, and drafting the manuscript. Mathieu Hylands and Francois Lamontagne coordinated the evidence search and synthesis and were guideline panel members. Annette Kristiansen was the methods chair for the guideline panel. Morten Mфller, Pierre Asfar, Dian Cohen, Rachel Khadaroo, Jon Laake, 
Anders Perner, Teddie Tanguay, Sandy Widder, and Per Vandvik were panel members, contributed significantly to formulating the recommendation, and provided edits to the manuscript.

\section{References}

1. Batistaki $C$, Kostopanagiotou $G$, Myrianthefs $P$, et al. Effect of exogenous catecholamines on tumor necrosis factor alpha, interleukin-6, interleukin-10 and beta-endorphin levels following severe trauma. Vascular Pharmacol 2008; 48: 85-91.

2. Sperry JL, Minei JP, Frankel HL, et al. Early use of vasopressors after injury: caution before constriction. J Trauma 2008; 64: 9-14.

3. Van Haren RM, Thorson CM, Valle EJ, et al. Vasopressor use during emergency trauma surgery. Am Surg 2014; 80: 472-8.
4. Plurad DS, Talving P, Lam L, Inaba K, Green D, Demetriades D. Early vasopressor use in critical injury is associated with mortality independent from volume status. J Trauma 2011; 71: 565-70; discussion 570-2.

5. Cohn SM, McCarthy J, Stewart RM, Jonas RB, Dent DL, Michalek $J E$. Impact of low-dose vasopressin on trauma outcome: prospective randomized study. World J Surg 2011; 35: 430-9.

6. Hemkens LG, Contopoulos-Ioannidis DG, Ioannidis JP. Agreement of treatment effects for mortality from routinely collected data and subsequent randomized trials: metaepidemiological survey. BMJ 2016; 352: i493.

7. Beloncle $F$, Meziani F, Lerolle N, Radermacher P, Asfar P. Does vasopressor therapy have an indication in hemorrhagic shock? Ann Intensive Care 2013; 3: 13. 